\title{
Ranges of obligate coral-dwelling crabs extend northward as their hosts move north
}

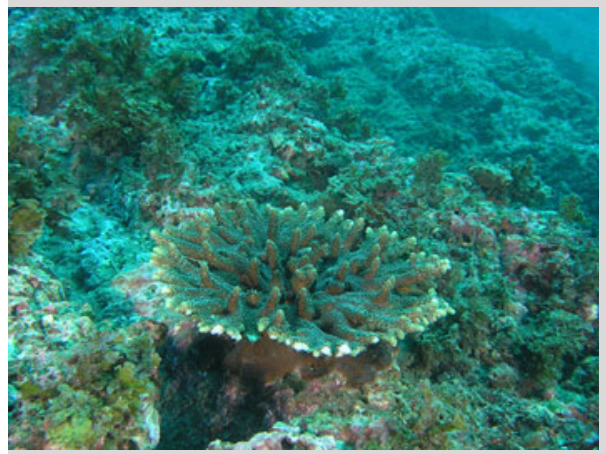

Fig. 1 One of the northernmost Acropora solitaryensis colonies at Tateyama, Japan
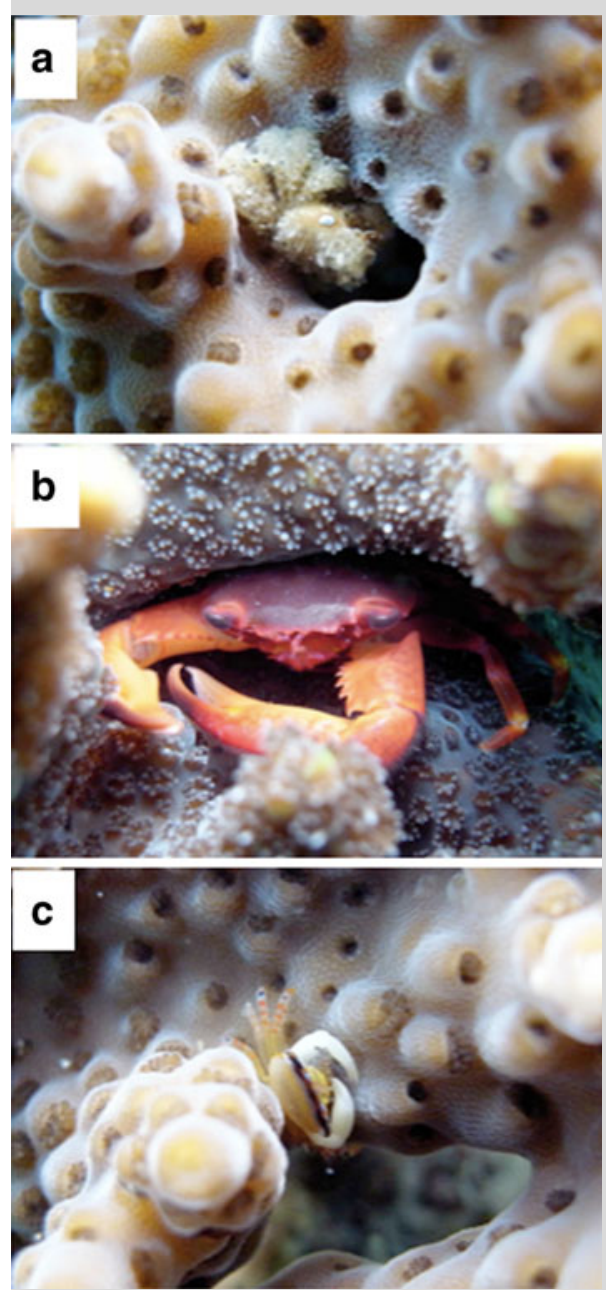

Fig. 2 Obligate coral-dwelling crabs associated with the northernmost Acropora solitaryensis colonies. a Cymo melanodactylus, b Trapezia cymodoce, and $\mathbf{c}$ Tetraliidae sp.
Recent sea-surface temperature warming may allow poleward range expansions of warm-water coral species into temperate areas. In Japan, Acropora solitaryensis Veron and Wallace, 1984 showed a poleward range expansion to Tateyama, on the southern tip of the Boso Peninsula $\left(34^{\circ} 59^{\prime} \mathrm{N}\right.$ and $\left.139^{\circ} 47^{\prime} \mathrm{E}\right)$, based on the historical occurrence records and recent surveys (Yamano et al. 2011). The Boso Peninsula is located downstream of the Kuroshio warm current and is the northernmost known coral community in the Pacific, although it is located beyond the limit of the coral reef distribution (Shimoike 2004).

In July 2011, we observed five A. solitaryensis colonies on sedimentary rock substrate at water depths of $\sim 12 \mathrm{~m}$ in Tateyama (Fig. 1). Four of the colonies served as hosts for obligate coral-dwelling crabs, Cymo melanodactylus Dana, 1852 (on one A. solitaryensis colony) (Fig. 2a), Trapezia cymodoce (Herbst, 1801) (on two colonies) (Fig. 2b), and Tetraliidae sp. (on one colony) (Fig. 2c). These were the northernmost records for A. solitaryensis and its associates $C$. melanodactylus and T. cymodoce in their distribution ranges (Minemizu 2000). The radius of A. solitaryensis colonies ranged from 6 to $15 \mathrm{~cm}$, suggesting that settlement occurred several years between 1994 and 2004, according to the published radius expansion rate $(0.9 \mathrm{~cm} /$ year; Yamano et al. 2011). Our observations suggest rapid establishment by crab symbionts after warm-water coral settlement, which may lead to changes in biodiversity in temperate areas during global warming.

Acknowledgments We thank Hitoshi Narita for field support. This research was supported by the Ministry of the Environment, Japan (Project No. S-9), and the Monitoring Project for Global Warming Effects on Marine Environments in the National Institute for Environmental Studies, Japan, and The Oceanic Wildlife Society.

\section{References}

Minemizu R (2000) Marine decapod and stomapod crustaceans mainly from Japan. Bun-ichi Sogo Shuppan, Tokyo

Shimoike K (2004) Boso Peninsula. In: Ministry of the Environment and Japanese Coral Reef Society (ed) Coral reefs of Japan. Ministry of the Environment, Tokyo, pp 232-233

Yamano H, Sugihara K, Nomura K (2011) Rapid poleward range expansion of tropical reef corals in response to rising sea surface temperatures. Geophys Res Lett 38:L04601. doi:10.1029/2010GL046474

H. Yamano $(\bowtie) \cdot$ K. Sugihara

National Institute for Environmental Studies, 16-2 Onogawa, Tsukuba,

Ibaraki 305-8506, Japan

e-mail: hyamano@nies.go.jp

K. Goto · T. Kazama $\cdot$ K. Yokoyama

The Oceanic Wildlife Society, 302 Stork-Zoshigaya, 3-11-2 Zoshigaya, Toshima,

Tokyo 171-0032, Japan

\section{J. Okuno}

Coastal Branch of Natural History Museum and Institute, Chiba, 123 Yoshio, Katsuura, Chiba 299-5242, Japan 